\title{
INTERVENTIONS TO ENCOURAGE AND SUPPORT BREASTFEEDING
}

\section{Debra Hector}

NSW Centre for Public Health Nutrition

University of Sydney

\section{Lesley King}

NSW Centre for Overweight and Obesity

University of Sydney

The need for effective interventions to encourage and support optimal breastfeeding practices has been established. ${ }^{1,2}$ The previous paper in this issue discusses the range of potential factors that influence breastfeeding practices. ${ }^{3}$ This article provides an overview of the potential interventions that address these factors. It also summarises the findings of an evaluation of systematic reviews and meta-analyses of interventions that has recently been published in the report 'Overview of recent reviews of interventions to promote and support breastfeeding' ${ }^{4}$

\section{POTENTIAL INTERVENTIONS TO PROMOTE BREASTFEEDING}

The conceptual framework of factors that influence breastfeeding practices, described in the previous paper, ${ }^{3}$ provides a basis for identifying potential interventions. Table 1 shows the links between these factors, typical breastfeeding strategy objectives and examples of potential interventions. There is congruence between the types of interventions outlined in Table 1 to promote breastfeeding, and the five generic health promotion action areas given in the Ottawa Charter for Health Promotion ${ }^{5}$ : develop personal skills, reorient health services, create supportive environments, build healthy public policy, and strengthen community action.

\section{Individual level factors}

Prenatal interventions need to encourage mothers to breastfeed. Early postnatal interventions aim to increase breastfeeding-related knowledge and practical skills. Interventions that facilitate or maintain the good health status of mother and infant are also required. Education, professional support and peer support are the main types of intervention at the individual level.

\section{Group level factors}

Hospital practices can ensure that the conditions immediately after birth and during the hospital stay are conducive to and supportive of breastfeeding. Health professional training is aimed at ensuring that mothers receive consistent, relevant, and useful advice with respect to breastfeeding practices and problems. Provision of, and referrals to, well-coordinated postnatal breastfeeding support services (for example, lactation consultants) is an objective of the hospital and health service environment that contributes to the mother's maintenance of breastfeeding. Public policies such as those that limit the marketing of breastmilk sub- stitutes in hospitals ensure that the decision to breastfeed is not undermined by, for example, mothers being given hospital discharge packs of infant formula.

After being discharged from hospital, mothers need help to maintain exclusive breastfeeding for several months. Creating a home and family environment that is conducive to exclusive breastfeeding may require strategies such as increasing appropriate support (for example, family support services) and strengthening breastfeeding and parenting skills, along with advocacy for public policies (for example, maternity/paternity benefits).

Interventions that enable women to combine work and breastfeeding are crucial. Supportive work environments require the provision of, and underlying policies for, physical facilities that enable mothers to breastfeed and/or to express and store breastmilk for later feeding (such as private rooms and access to refrigeration). Flexible employment practices (including parental leave), breaks from work, and circulars to staff about breastfeeding-friendly workplaces are necessary. Such workplace policies help create norms about the acceptability of combining breastfeeding and working.

Support from community members and organisations, together with advocacy for public facilities and policies that make breastfeeding easier outside the home, are needed. Examples of interventions include lay and peer support groups for breastfeeding, feeding/parenting rooms in public places, and breastfeeding-friendly businesses.

\section{Society level factors}

The objectives of strategies to influence the wider social, cultural and economic environment include promoting social norms that encourage breastfeeding, and social roles for men and women that are consistent with good breastfeeding practices. Advocating for reforms in the economic and health systems to provide structures and incentives for breastfeeding are important. Examples of such interventions include social marketing (including media campaigns); high school curricula dealing with parenting skills and norms and sexuality; health insurance incentives for breastfeeding; and implementation of the WHO Code for marketing of breastmilk substitutes. ${ }^{6}$

Healthy public policy is an overarching strategy that aims to modify environments, including the broader social, cultural and economic environments, to support mothers to initiate and maintain breastfeeding.

\section{SYSTEMATIC REVIEWS OF INTERVENTIONS TO PROMOTE BREASTFEEDING}

Evidence-based practice relies on the findings of sound evaluation research to determine whether an intervention is likely to be effective. ${ }^{7,8}$ Systematic reviews and meta- 


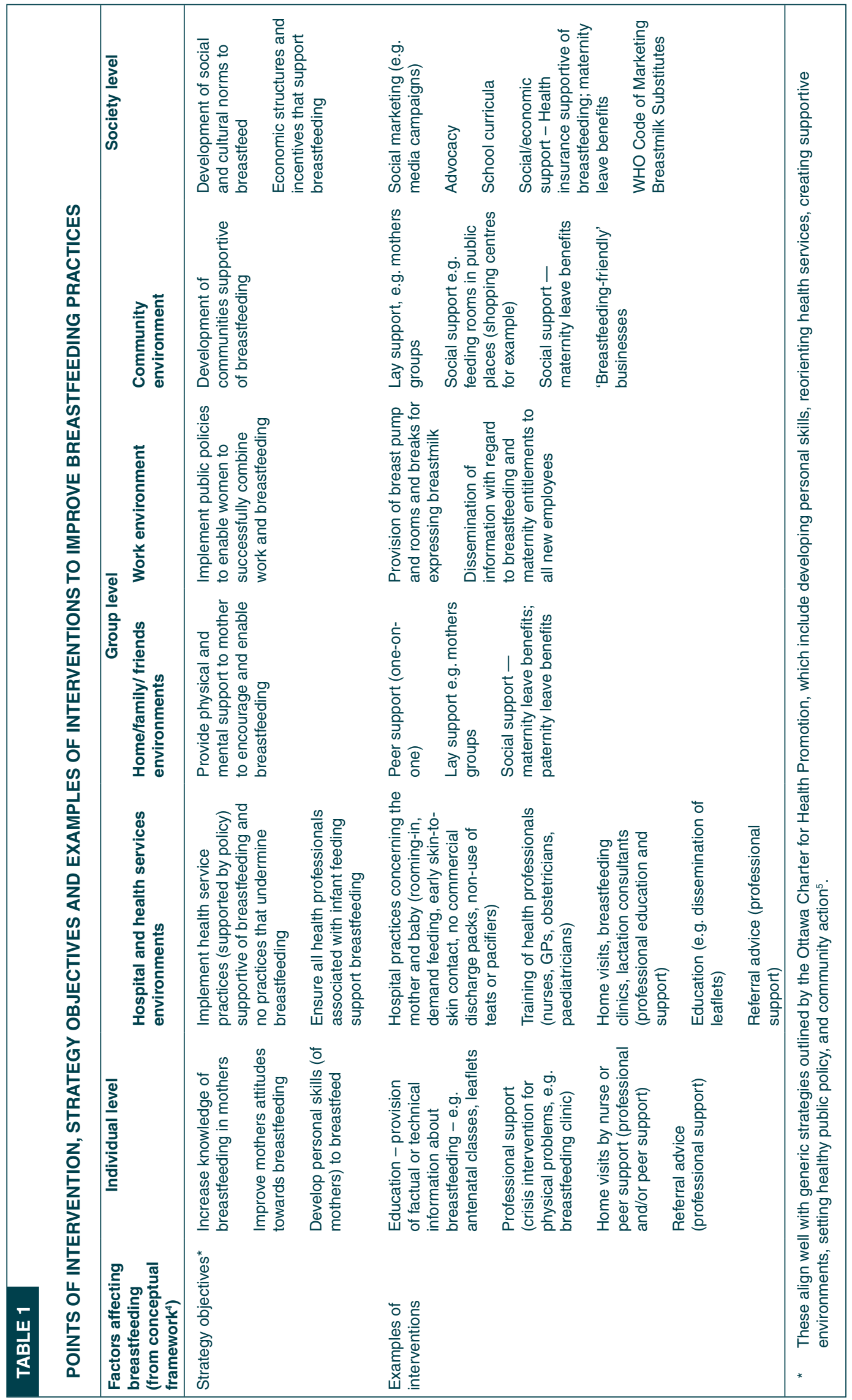




\section{TABLE 2}

\section{SUMMARY OF THE MAGNITUDE OF EFFECT (DERIVED FROM META-ANALYSES) OF DIFFERENT TYPES OF INTERVENTIONS ON BREASTFEEDING PRACTICES}

\begin{tabular}{|c|c|c|c|c|}
\hline Review & Intervention & Breastfeeding outcome & Measure of effect & $95 \% \mathrm{Cl}$ \\
\hline \multirow[t]{2}{*}{$\begin{array}{l}\text { Anderson et al } \\
(2003)^{12}\end{array}$} & Early skin-to-skin contact & $\begin{array}{l}\text { Still breastfeeding (any) } \\
\text { at } 1-3 \text { months post-birth }\end{array}$ & $\mathrm{OR}^{*} 2.15$ & $(1.10,4.22)$ \\
\hline & & Duration & $\mathrm{WMD}^{\dagger} 41.99$ days & $(13.97,70.00)$ \\
\hline \multirow{6}{*}{$\begin{array}{l}\text { USPSTF } \\
(2003)^{13,14}\end{array}$} & Breastfeeding education & Initiation & difference $^{\ddagger} 0.23$ & $(0.12,0.34)$ \\
\hline & & $\begin{array}{l}\text { Short-term duration } \\
\text { (<3 months) }\end{array}$ & difference 0.39 & $(0.27,0.50)$ \\
\hline & Support alone & $\begin{array}{l}\text { Short-term duration } \\
\text { (1-3 months) }\end{array}$ & difference 0.11 & $(0.03,0.19)$ \\
\hline & & $\begin{array}{l}\text { Long-term duration } \\
\text { (4-6 months) }\end{array}$ & difference 0.08 & $(0.02,0.16)$ \\
\hline & Education plus Support & Initiation & difference 0.21 & $(0.07,0.35)$ \\
\hline & & Short-term duration & difference 0.37 & $(0.17,0.58)$ \\
\hline \multirow[t]{10}{*}{ Sikorski et al (2001) ${ }^{11}$} & Support (all types) & Duration & $\begin{array}{l}\text { RR (for stopping breastfeeding } \\
\text { before last study assessment up } \\
\text { to six months) } 0.88^{\S}\end{array}$ & $(0.81,0.95)$ \\
\hline & & Exclusive breastfeeding & $\begin{array}{l}\text { RR (for stopping exclusive } \\
\text { breastfeeding before last study } \\
\text { assessment) } 0.78\end{array}$ & $(0.60,0.89)$ \\
\hline & Professional support & Duration & $\begin{array}{l}\text { RR (for stopping breastfeeding } \\
\text { before last study assessment up } \\
\text { to } 6 \text { months) } 0.89\end{array}$ & $(0.81,0.97)$ \\
\hline & & Exclusive breastfeeding & $\begin{array}{l}\text { RR (for stopping exclusive } \\
\text { breastfeeding before } 4-6 \text { wks) } \\
0.50\end{array}$ & $(0.27,0.90)$ \\
\hline & & & $\begin{array}{l}\text { RR (for stopping exclusive } \\
\text { breastfeeding before } 2 \text { months) } \\
0.76\end{array}$ & $(0.61,0.94)$ \\
\hline & Lay support & Duration & $\begin{array}{l}\text { RR (for stopping breastfeeding } \\
\text { before last study assessment) } \\
0.84\end{array}$ & $\begin{array}{l}(0.69,1.02) \\
\text { non significant } \\
\text { trend }\end{array}$ \\
\hline & & Exclusive breastfeeding & $\begin{array}{l}\mathrm{RR} \text { (for stopping exclusive } \\
\text { breastfeeding before last study } \\
\text { assessment) } 0.66\end{array}$ & $(0.49,0.89)$ \\
\hline & Face-to-face interventions & Duration & $\begin{array}{l}\text { RR for giving up breastfeeding } \\
0.86\end{array}$ & $(0.78,0.94)$ \\
\hline & Only Postnatal support & Duration & $\begin{array}{l}\text { RR for giving up breastfeeding } \\
0.88\end{array}$ & $(0.80,0.96)$ \\
\hline & WHO/UNICEF Training & $\begin{array}{l}\text { Prolonged exclusive } \\
\text { breastfeeding }\end{array}$ & $\begin{array}{l}\text { RR for giving up exclusive } \\
\text { breastfeeding } 0.70\end{array}$ & $(0.53,0.93)$ \\
\hline \multirow[t]{7}{*}{$\begin{array}{l}\text { Donnelly et al } \\
(2000)^{10}\end{array}$} & $\begin{array}{l}\text { Commercial hospital } \\
\text { discharge packs: }\end{array}$ & $\begin{array}{l}\text { Not exclusively } \\
\text { breastfeeding at: }\end{array}$ & Peto Odds Ratios"* $^{* *}$ & \\
\hline & $\begin{array}{l}\text { With formula promotional } \\
\text { material but no formula }\end{array}$ & $0-2$ weeks & 1.99 & $(1.04,3.79)$ \\
\hline & sample versus no & 3-6 weeks & 1.23 & $(1.05,1.43)$ \\
\hline & $\begin{array}{l}\text { intervention }{ }^{* *} \text { or non- } \\
\text { commercial packs }{ }^{\dagger \dagger}\end{array}$ & 8-10 weeks & 1.73 & $(1.13,2.64)$ \\
\hline & $\begin{array}{l}\text { With formula promotional } \\
\text { material + formula samples }\end{array}$ & 0-2 weeks & 1.99 & $(1.04,3.79)$ \\
\hline & $\begin{array}{l}\text { versus no intervention"or } \\
\text { non-commercial packs }{ }^{\dagger \dagger}\end{array}$ & 3-6 weeks & 1.25 & $(1.06,1.47)$ \\
\hline & $\begin{array}{l}\text { With formula promotional } \\
\text { material but no formula } \\
\text { sample versus no } \\
\text { intervention }^{11}\end{array}$ & 3-6 weeks & 1.27 & $(1.01,1.62)$ \\
\hline
\end{tabular}

* $\quad \mathrm{OR}=$ Odds Ratio. Mothers that experienced early skin-to-skin contact with their babies were over two times (2.15 times) more likely to be still breastfeeding at 1-3 months than mothers who did not experience early skin-to-skin contact with their babies.

$\dagger \quad W M D=$ Weighted mean difference. A statistical measure of difference used in meta-analysis. In this instance it means that mothers experiencing early skin-to-skin contact breastfed on average 42 days longer than mothers who didn't experience early skin-to-skin contact.

$\ddagger \quad$ 'difference' refers to the difference in proportion of mothers breastfeeding in the intervention group compared to the control group, i.e. 0.23 indicates that $23 \%$ more mothers were breastfeeding as indicated as a result of the intervention

$\S$ Sikorski et al ${ }^{11}$ present the measure of effect (relative risk) in terms of the risk to the breastfeeding practice, hence it is less than 1 . A smaller number indicates a larger, positive effect of the intervention in terms of improved breastfeeding practice.

** The Peto odds ratio is used in Cochrane meta-analyses as an approximation to the odds ratio. For example, mothers were nearly twice (1.73 times) as likely to be exclusively breastfeeding at 8-10 weeks if they did not receive a discharge pack containing formula promotional material

†† No intervention $=$ nothing was given to mothers leaving hospital

执 Non-commercial discharge packs contained an aid to breastfeeding, e.g. a breast pump or breast pads, or contained promotional literature on breastfeeding 
analyses identify, appraise and summarise the results of otherwise unmanageable quantities of research. They apply consistent criteria related to study type and aims, and select those studies that are of high quality, valid and provide evidence of effectiveness, to produce findings that can be applied in public health practice. This approach has been applied to the numerous studies evaluating interventions designed to improve breastfeeding practices.

Systematic reviews and meta-analyses of strategies for promoting and supporting breastfeeding published since 1995, when NSW Health last conducted a review of evaluation studies ${ }^{9}$, were identified in the literature. The range of reviews identified were appraised according to the approach recommended in A Schema for evaluating evidence on public health interventions. ${ }^{8}$

Nine good quality systematic reviews of breastfeeding interventions were found. Quantitative measures of the effect of particular interventions on breastfeeding outcomes were derived by meta-analysis in four of the reviews. ${ }^{10-14}$ The other five reviews ${ }^{15-20}$ did not provide quantitative measures of effect as it was considered that the primary studies were too dissimilar in terms of type of intervention(s), participants, and definitions of outcomes.

\section{Evidence of effectiveness}

The reviews, and the primary studies to which they relate, varied in terms of the outcome measures assessed; few evaluated effects of programs on duration of breastfeeding, particularly exclusive breastfeeding, beyond three months, and none examined the duration of breastfeeding beyond six months. Most studies, and therefore the reviews, were evaluated for effectiveness in terms of the duration of any breastfeeding, usually over the first few months postpartum.

Much of the available evidence from the systematic reviews relates to educational and support strategies designed to promote mothers' personal skills, and to hospital and health service environments (including particular practices, services, policies and training of health professionals) conducive to breastfeeding. The quantitative evidence from the meta-analyses is provided in Table 2 . It shows that the positive effect on breastfeeding is substantial for a number of interventions.

\section{TABLE 3}

INTERVENTIONS TO PROMOTE AND SUPPORT BREASTFEEDING: CONCLUSIONS FROM A SYNTHESIS OF FINDINGS OF SYSTEMATIC REVIEWS

Education

- Education alone is effective in increasing rates of breastfeeding initiation and short-term duration

- Content should include: benefits of breastfeeding, principles of lactation, myths, common problems and solutions, and skills training

- Formats most effective are one-to-one educational programs and/or small group programmes in an informal environment together with postnatal home visits

- Sessions spanning prenatal and postnatal periods are most effective

Support

- Increases the longer-term duration and exclusivity of breastfeeding

- Particularly effective in settings where there are high rates of breastfeeding initiation

- Must include face-to-face contact

- Effectiveness is enhanced by home visits

- Peer support increases both rates of breastfeeding initiation (among women who intend to breastfeed) and the duration of exclusive breastfeeding

- Peer support is particularly effective among socioeconomically disadvantaged women

- Peer counsellors are more successful if they are culturally and socially similar to mothers, available to advise on problems and answer questions, and contact is frequent

- Postnatal support alone increases breastfeeding duration

Combination of Education and Support

- Face-to-face education and peer counselling is particularly effective

Health Service Policy and Programs

- Explicit health service policies that outline appropriate health service practices are beneficial

- Specific in-hospital practices that support breastfeeding are: early skin-to-skin contact between the baby and mother, rooming-in, not giving commercial hospital discharge packs, not using supplemental feeds, and not using artificial teats and pacifiers

- A Cochrane review ${ }^{11}$ indicated that WHO/UNICEF training courses for in-hospital health professionals increased the likelihood of prolonged exclusive breastfeeding by $30 \%$

- The combination of policy, in-hospital practices and professional training is effective in improving breastfeeding practices

Multifaceted interventions

- Multifaceted interventions have been shown to be effective at increasing the initiation and, in most cases, duration of breastfeeding in developed countries

- The optimal mix of interventions will depend on the setting, however packages including two or more of the following have been shown to be effective in improving breastfeeding practices: education of mothers, peer support, changes to hospital practices such as rooming-in and early skin-to-skin contact, staff training, development and implementation of hospital policy, media campaigns/programs, paid maternity leave

Source: Overview of recent reviews of interventions to promote and support breastfeeding'. ${ }^{4}$ 
Specific hospital practices such as skin-to-skin contact ${ }^{12}$ and not giving commercial discharge packs ${ }^{10}$ lead to more women beginning to breastfeed, and increase the length of time that women breastfeed in the short term. For example, early skin-to-skin contact has been shown to increase the length of time mothers breastfeed by 42 days. Other specific hospital practices, such as rooming-in, are also effective. ${ }^{16}$

A summary of the major findings synthesised from the nine systematic reviews is presented in Table 3.

Evidence and experience indicates that health service policy and professional training can be important in enabling the consistent and integrated adoption and implementation of recommended practices. Health service policy and health professional training are integral components of the 'Ten steps to successful breastfeeding, ${ }^{21}$ the Baby Friendly Hospital Initiative, ${ }^{22}$ and the 'Seven point plan for the protection, promotion and support of breastfeeding in community health settings' ${ }^{23}$

Overall, meta-analyses and narrative systematic reviews indicate that well conducted educational and support interventions have substantial and significant effects on breastfeeding initiation and short-term duration (up to three months). Both peer and professional support strategies have been found to have a significant impact on shortterm duration and exclusivity of breastfeeding. Combined educational and support interventions are effective; and a mix of prenatal and postnatal contacts appears to be optimal. Postnatal home visiting appears to be particularly beneficial.

There is some evidence that multifaceted interventions are likely to be effective but the optimal mix of interventions is unknown.

\section{DISCUSSION}

The appraisal of systematic reviews identifies educational, support and health service interventions for which the evidence of effectiveness is abundant and convincing. This evidence therefore provides a basis for recommendations to strengthen the implementation of these types of interventions in NSW and Australian health services.

Recent national and international health strategies, such as the National Breastfeeding Strategy ${ }^{24}$, the Global Strategy for Infant and Young Child Feeding ${ }^{25}$, and the United States Department of Health and Human Services 'Blueprint for action on breastfeeding, ${ }^{26}$, advocate the use of a broad range of interventions to promote breastfeeding, including those for which evidence is currently limited, such as workplace initiatives. Similarly, the recent Dietary Guidelines for Children and Adolescents in Australia and the Infant Feeding Guidelines for Health Workers ${ }^{27}$ promote a comprehensive approach to breastfeeding promotion and support. Given the numerous and complex influences on breastfeeding, and the range of potential strategies that are not covered by systematic reviews, a comprehensive policy and set of programs should comprise a broad range of interventions covering individual, group (hospital and health services, home and family, work and community), and societal level determinants.

It is equally important that interventions are evaluated to provide evidence of effectiveness to fill the many evidence gaps that remain.

The report Overview of recent reviews of interventions to promote and support breastfeeding is available on the CD that accompanies this special edition of the NSW Public Health Bulletin. The report can also be downloaded from www.cphn.biochem.usyd. edu.au/resources/OverviewBreastfeeding.pdf. Print copies can be obtained from:

NSW Centre for Public Health Nutrition, Medical Foundation Building K25, University of Sydney, NSW 2006.

A copy of the WHO report Implementing the global strategy for infant and young child feeding is also available on the CD.

\section{REFERENCES}

1. Hector D, Webb W. Describing breastfeeding practices in NSW using data from the NSW Child Health Survey, 2001. N S W Public Health Bull 2005; 16 (3-4):47-51.

2. Hector D, Webb K, Lymer S. State of food and nutrition in $N S W$ series: report on breastfeeding in NSW. Sydney. NSW Department of Health; 2004 (Revised 2005).

3. Hector D, King L, Webb K, Heywood P. Factors affecting breastfeeding practices. Applying a conceptual framework. N S W Public Health Bull 2005; 16 (3-4):52-55.

4. Hector D, King L, Webb K. State of food and nutrition in NSW series: Overview of recent reviews of interventions to promote and support breastfeeding. Sydney. NSW Department of Health; 2004.

5. Ottawa Charter for Health Promotion $1986.1^{\text {st }}$ International Conference on Health Promotion, Ottawa, Canada, 21 November 1986 - WHO/HPR/HEP/95.1

6. World Health Organization. The International Code of Marketing of Breast-milk Substitutes: A common review and evaluation framework, WHO, Geneva; 1996.

7. Sackett DL, Rosenberg WMC, Gray MJA, Haynes RB, Richardson WS. Evidence based medicine: what it is and what it isn't. Br Med J 1996; 312: 71-72,

8. Rychetnik L, Frommer M. A schema for evaluating the evidence on public health interventions, Version 4. Melbourne. National Public Health Partnership Secretariat; 2002.

9. Stickney B, Webb K. Strategies to promote breastfeeding: an overview. Sydney. NSW Health Department: Health Promotion Branch, 1995. State Health Publication No. (HP) 950142.

10. Donnelly A, Snowden HM, Renfrew MJ, Woolridge MW. Commercial hospital discharge packs for breastfeeding women. Cochrane Database Syst Rev 2000; 2 (most recent update 24 April 2000). 
11. Sikorski J, Renfrew MJ, Pindoria S, Wade A. Support for breastfeeding mothers. Cochrane Database Syst Rev 2002; 1 (most recent update 21 January 2001).

12. Anderson GC, Moore E, Hepworth J, Bergman N. Early skin-to-skin contact for mothers and their healthy newborn infants. Cochrane Database Syst Rev 2003; 2 (most recent update 22 April 2003).

13. U.S. Preventive Services Task Force. The effectiveness of primary care-based interventions to promote breastfeeding: evidence review and meta-analysis for the U.S. Preventive Services Task Force. Ann Fam Med 2003a; 1(2): 70-78. Available at www.ahrq.gov/clinic/3rduspstf/brstfeed/ brfeedsum.pdf, accessed 16 June 2005.

14. U.S. Preventive Services Task Force. Behavioural interventions to promote breastfeeding: Recommendations and rationale. Ann Fam Med 2003b 1(2): 79-80. Available at www.ahrq. gov/clinic/3rduspstf/brstfeed/brfeedrr.pdf, accessed 16 June 2005.

15. Tedstone AE, Dunce NA, Aviles M, Shetty PS, Daniels LA. Effectiveness of interventions to promote healthy feeding in infants under one year of age: a review. Health Promotion Effectiveness Review: Summary Bulletin 09. Health Education Authority 1998. http://healthpromis.had-online.org.uk/ Archimages/225.pdf.

16. World Health Organization. Evidence for the ten steps to successful breastfeeding. WHO/CHD/98.9. Division of Child Health and Development. Geneva, 1998. Available at www. who.int/reproductive-health/docs/breastfeeding.pdf, accessed 16 June 2005.

17. Green CP. Interventions to improve breastfeeding behaviours: Detailed summaries of 51 studies 1999a; http://linkagesproject.org/media/publications/Technical\%/ 20Reports/InterventionsGreentables.pdf.

18. Green CP. Improving breastfeeding behaviours: Evidence from two decades of intervention research 1999b; http://linkagesproject.org/media/publications/ Technical\%20Reports/ImprovBFBehav.pdf.

19. Fairbank L, O’Meara S, Renfrew MJ, Woolridge MW, Sowden A, Lister-Sharp D. A systematic review to evaluate the effectiveness of interventions to promote the initiation of breastfeeding. Health Tech Assess 2000; 4(25): www.ncchta. org/fullmono/mon425.pdf, accessed 16 June 2005.

20. de Oliveira MI, Camacho LA, Tedstone AE. Extending breastfeeding duration through primary care: a systematic review of prenatal and postnatal interventions. J Hum Lact 2001; 7(4): 326-343.

21. World Health Organisation, UNICEF. Protecting, promoting and supporting breastfeeding: the special role of maternity services, WHO/UNICEF, 1989.

22. UNICEF. Baby-Friendly Hospital Initiative and programme manual. Geneva, 1992.

23. Seven point plan for the protection, promotion and support of breastfeeding in community health care settings. In: $A$ brief guide for health professionals, UNICEF, UK. www. babyfriendly.org.uk/commun.asp

24. Commonwealth Department of Health and Ageing. National Breastfeeding Strategy (1996-2001): Summary Report. Commonwealth of Australia, 2001.

25. World Health Organization. Global strategy for infant and child feeding. Singapore. WHO/UNICEF; 2003.

26. US Department of Health and Human Services, HHS blueprint for action on breastfeeding, Washington D.C. US Department of Health and Human Services, Office on Women's Health, 2000.

27. National Health and Medical Research Council. Dietary Guidelines for Children and Adolescents, incorporating the Infant Feeding Guidelines for Health Workers. Canberra: Commonwealth of Australia; 2003. 돟 